\title{
INTERNATIONAL BORROWING: A REPLY TO ROLF MIRUS'S NOTE
}

\author{
JAMES V. JUCKER \\ Stanford University
}

Rolf Mirus starts his note on international borrowing by describing the "approach" which Clovis de Faro and I took in our JIBS article as that of ". . . picking the [borrowing] source with least expected cost without consideration of the risk involved."1 This characterization of our work is somewhat unfortunate, since we assumed, for purposes of clarity and simplicity, that the borrowing problems considered were situated in a deterministic (i.e., riskless) world. Specifically, we assumed that ". . . the inflation rates and devaluation rates expected during a loan period are always realized."2 Perhaps we should have repeated this assumption at the end of the paper and emphasized the limitations that this places on our results. Had we done this we might well have included something along the lines of the following: "That a firm in a risky world may refrain from raising all of its required funds in a lower cost foreign market is not contrary to the simple decision rule developed here, for our rule was developed for a riskless world.'

Mirus uses a mean-variance framework to show why firms may diversify their borrowing sources when they have international borrowing opportunities. I have little argument with what Mirus presents, but I think that it might be useful to look at the other side of the coin and see why firms may choose not to diversify. There are at least three cases in which a firm may choose to borrow from a single foreign source, even though the effective (after devaluation) borrowing rate from this source may be uncertain. First, it may be the firm's assessment that, although there is some uncertainty about the exchange rates at the end of the loan period, there is no chance that the exchange rates will change relative to one another in a manner that will make the a priori lowestcost borrowing source become the second-lowest-cost source. This is the case of uncertainty without risk. Second, there is the case of the risk-indifferent decision-maker. As Mirus has observed such a decision-maker will choose the source with the lowest expected cost regardless of the risk involved. Third, there is the case wherein the availability of forward exhange may reduce the set of interesting borrowing sources to but one foreign source. That is, it might be that for a given country $Z$ the sum of the premium paid for buying the currency of country $Z$ forward and the expected cost of borrowing in country $Z$ is less than the expected cost of borrowing anywhere else. In this case the firm would choose to borrow all of its funds from country $Z$ and reduce its risk by buying some amount of country $Z$ currency forward. The amount purchased forward would be between zero and the amount borrowed, depending on the degree to which country $Z$ borrowing is risky and the degree to which the decision-maker for the firm is risk averse. In the first two of these three cases, the simple decision rule developed in our JIBS article will suffice. The third case requires a more sophisticated analysis to help the decision-maker decide how much forward exchange to purchase. The mean-variance framework should prove useful for this.

1. Rolf Mirus, "The Impact of Inflation and Devaluation on the Selection of an International Borrowing Source: A Note," Journal of International Business Studies, this issue.

2. Clovis de Faro and James V. Jucker, "The Impact of Inflation and Devaluation on the Selection of an International Borrowing Source," Journal of International Business Studies 4 (Fall 1973), pp. 97-104.

* James V. Jucker is Associate Professor of Industrial Engineering at Stanford University. 